\title{
Modeling Corporate Environmental Responsibility Perceptions and Job-Seeking Intentions: Examining the Underlying Mechanism
}

\author{
Md Sohel Chowdhury (D) and Dae-seok Kang * \\ Graduate School of Business Administration, Inha University, Incheon 22212, Korea; sohel@inha.edu \\ * Correspondence: kang0180@inha.ac.kr; Tel.: +82-32-860-7751
}

check for updates

Citation: Chowdhury, M.S.; Kang, D.-s. Modeling Corporate Environmental Responsibility Perceptions and Job-Seeking Intentions: Examining the Underlying Mechanism. Sustainability 2021, 13, 6270. https://doi.org/ $10.3390 /$ su13116270

Academic Editor: Ştefan Cristian Gherghina

Received: 26 April 2021

Accepted: 28 May 2021

Published: 1 June 2021

Publisher's Note: MDPI stays neutral with regard to jurisdictional claims in published maps and institutional affiliations.

Copyright: (c) 2021 by the authors. Licensee MDPI, Basel, Switzerland. This article is an open access article distributed under the terms and conditions of the Creative Commons Attribution (CC BY) license (https:/ / creativecommons.org/licenses/by/ $4.0 /)$.

\begin{abstract}
This study aims to propose and empirically test a research model to examine the relationship between prospective employees' corporate environmental responsibility (CER) perceptions and their attraction to an organization based on social theories. This may be the first study to elucidate how CER perceptions can influence prospective employees' job-seeking intentions by exploring the sequential mediating mechanism of organizational trust and job-seeking attitudes in a prehire context. Collecting data from a sample of 357 young prospective employees, the research hypotheses were tested using path analysis with AMOS (version 24), a structural equation modeling (SEM) program. The study results revealed direct association of CER perceptions and job-seeking attitudes with job-seeking intentions. Observably, the organizational trust could not predict job-seeking intentions. However, organizational trust and job-seeking attitudes together sequentially and partially mediated the direct effects of CER perceptions on job-seeking intentions. In line with the research findings, some notable theoretical contributions and practical implications for HR professionals have been discussed. The paper concludes by presenting some limitations and future research directions.
\end{abstract}

Keywords: corporate environmental responsibility; job-seeking; organizational trust; prospective employees; sequential mediation

\section{Introduction}

A considerable body of research demonstrates that a firm's environmental activities can be a key checkpoint for improving its organizational attractiveness to future human resources. In this respect, extant research has investigated the relationship between prospective applicants' perceptions about a firm's corporate environmental responsibility (CER) and their intentions to apply for jobs in the firm. However, despite the continuous call for an underlying process via which CER perceptions influence millennials' job-seeking intentions, little research has empirically examined the role of psychological factors in the above relationship [1,2]. Furthermore, while many researchers have focused on the effects of organizational trust on existing employees' performance and commitment (e.g., [3,4]), trust research on job-seeking literature for prospective employees is very limited. This suggests that the impacts of organizational trust are largely applicable to existing employees of an organization, leaving an important gap in the literature. Another salient aspect widely overlooked in the past studies is that most research so far centered heavily on the Western context, and empirical investigation on the applicability of a theory-driven model of job-seeking is very limited in Asian societies [5,6], even less so in the context of Bangladesh.

To address these research gaps, we propose a theory-based model to examine the role of psychological factors that seem to be salient in the linkage between prospective employees' CER perceptions and their job-seeking intentions. Drawing on CER perceptions in a pre-entry recruitment context, we argue that organizational trust and job-seeking attitudes may together serve as a sequential mediating mechanism for pulling the instrumental side 
of a firm's environmental orientations so that potential applicants' CER perceptions act to align their job-seeking intentions. Although past studies reported the influence of those psychological factors on talent attraction separately, none of those studies considered them to explain the above linkage in a single framework, ignoring the plausible correlations among them. Failing to understand the underlying process of the above linkage may result in a small size of the potential applicant pool, which consequently may lead to the loss of a firm's competitive advantage [7]. Although the recruitment process of a firm generally consists of attracting potential candidates, maintaining them in the applicant pool, and influencing their job choices [8], applicant attraction is the most important phase, and is especially critical for HR professionals. Because they need to allow potential candidates access to more organizational information to influence their job-seeking intentions [9], making job-seeking research more appealing, Bangladesh is not an exception to this phenomenon.

Therefore, our study makes several significant contributions to the field in the following ways. First, this study examines how and when the influence of prospective employees' CER perceptions becomes more instrumental. Probing the underlying process of how CER perceptions shape prospective employees' job-seeking intentions through more proximal outcomes of psychological factors advances the growing body of knowledge in career-related actions, responding to a call from early researchers (e.g., [10,11]). Second, by examining the serial mediating roles of salient psychological factors, this study contributes to the theoretical development of job-seeking literature that until now has not evidently provided clear paths from CER perceptions to job-seeking intentions among millennials in Asian cultures, even far less so in the context of Bangladesh. Third, the present study is expected to expand and integrate two separate streams of previous research on job-seeking literature: (1) research that examined the effects of CER perceptions on job-seeking intentions, but ignored the process through which their effects might occur; and (2) research that investigated how job seekers' perception of organizational trust influenced their intentions to accept a job offered by the company, but overlooked the causal mechanism through which the influence might occur. All in all, this study attempts to extend past research by building a critical bridge between prospective employees' CER perceptions on one side and their job-seeking intentions on the opposite side through exploring the sequential mediating mechanism of organizational trust and job-seeking attitudes in a pre-entry recruitment context.

\section{Theoretical Background and Hypotheses}

In this section, we articulate job-seeking literature in relation to prospective employees' CER perceptions based on social theories in a prehire context. A wide range of literature in the related field has been reviewed to develop the theoretical framework and research hypotheses for this study, expecting it to be more contributory to explain the relationship between CER perceptions and job-seeking intentions through exploring the chain-mediating mechanism of psychological factors such as organizational trust and job-seeking attitudes. Figure 1 depicts our hypothesized research model for this study.

Past studies indicated that offering only an attractive compensation package is no longer sufficient to increase organizational attractiveness to potential employees nowadays [2]. Research demonstrated that people's awareness about environmental efforts of a company has notably increased in developing countries [12]. Despite having various social and economic problems, Bangladesh is one of those developing countries that embeds environmental sustainability issues alongside economic growth, and the country is committed to meeting sustainability development goals (SDGs) [13]. Because of the growing importance of environmental sustainability for the economic development of a country, the concept of CER has attracted intensive research attention [11]. Perceived CER refers to stakeholders' thoughts about a firm's level of commitment to reduce its environmental impacts [14]. In a more recent study conducted by Torelli et al. [15], an organization's environmental activities were claimed to be appreciable in the eyes of its customers, employees, prospective job applicants, and various stakeholders. Hanson-Rasmussen et al. [16] argued 
that an environmentally oriented firm tends to enjoy a competitive advantage over its competitors because it is more attractive to job seekers. Similarly, Carballo-Penela et al. [17] noted that job seekers in the millennial generation are more aware of the importance of a firm's sustainability efforts than those in the previous generations. Therefore, ignoring the importance of CER perceptions may lead to the loss of a firm's opportunity to boost its attractiveness to prospective employees, which consequently may result in the loss of a talented pool of applicants for job openings.

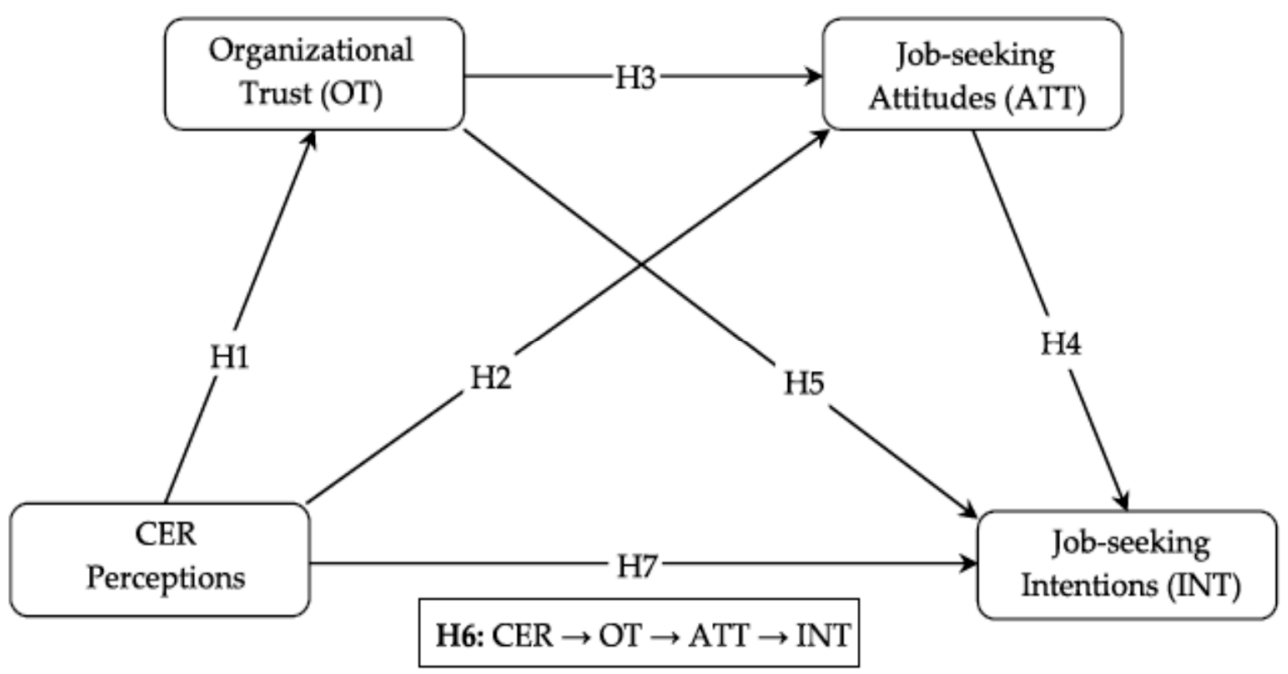

Figure 1. Hypothesized research model.

\subsection{CER Perceptions and Organizational Trust}

There are many angles through which the term "trust" can be defined. However, one of the most influential definitions of trust is "the willingness of a party to be vulnerable to the actions of another party based on the expectation that the other will perform a particular action important to the trustor" ([18], p.712). From prospective employees' standpoint, organizational trust refers to their cognitive belief that the recruiting firm will not do anything harmful; rather, it will perform particular functions important to them [19]. A company's environmental orientations provide evidence of its character and principles that help to create trust in the company [20]. In a similar vein, consumer research argued that one of the most immediate results of a firm's environmental efforts is the development of stakeholder's trust in the firm [21]; therefore, when applied to the present study, it is also reasonable to expect that potential candidates' perceptions about a firm's CER activities affect their organizational trust. This line of argument is also logical when seen through the lens of the signal theory [22], which suggests that a firm's CER activities provide signals about its norms and values, based on which prospective employees develop their trust that the hiring firm will not harm them, and will instead carry out specific functions essential to them. Thus, we developed our first hypothesis:

Hypothesis 1 (H1). CER perceptions positively affect organizational trust.

\subsection{CER Perceptions and Job-Seeking Attitudes}

According to Ajzen's [23] theory of planned behavior (TPB), attitudes refer to a person's emotional thoughts about an action. When applied to job-search literature, job-seeking attitudes refer to a person's feelings or perceptions about job-seeking [24]. As a firm's CER activities often provide hints to its stakeholders about its organizational values and norms, it is highly probable that such activities influence job seekers' attitudes toward searching for jobs in the firm. Given that prospective employees' perceptions about a firm's CER efforts significantly affect their job-seeking intentions [25], it is also reasonable to expect that they consider searching for jobs in the firm is a worthwhile activity (i.e., job-seeking 
attitudes). Another justification for our argument is based on the social identity theory [26], which suggests that individuals' job-seeking attitudes are likely to be influenced by their perceptions about a firm's CER efforts due to their desire to grow their self-esteem by working in an environmentally oriented firm. Therefore, we hypothesized that:

Hypothesis 2 (H2). CER perceptions positively affect job-seeking attitudes.

\subsection{Organizational Trust, Job-Seeking Attitudes, and Job-Seeking Intentions}

Intention refers to the degree of willingness of a person to perform an action [27]. When applied to the job-seeking literature, it refers to individuals' degree of willingness to engage themselves in job-seeking. Marketing research evidently confirmed that consumers' trust in an environmentally oriented firm has significant association with their attitudes toward purchasing products of the firm [21]. When we adapt the marketing research to the job-seeking literature, it is more likely that job seekers' trust in an environmentally oriented firm should influence their attitudes toward searching for jobs in the firm. Additionally, past studies demonstrated a significant influence of job-seeking attitudes on job-seeking intentions [28]. For instance, Leenders et al. [29] documented a significant positive relationship between job-seeking attitudes and job-seeking intentions among potential employees in the Netherlands. The TPB also suggests that individuals' job-seeking intentions are influenced by their attitudes toward job-seeking. Therefore, we devised the following two hypotheses:

Hypothesis 3 (H3). Organizational trust positively affects job-seeking attitudes.

Hypothesis 4 (H4). Job-seeking attitudes positively affect job-seeking intentions.

\subsection{Organizational Trust and Job-Seeking Intentions}

As noted earlier, organizational trust is associated with an individual's cognitive belief or conviction, while job-seeking intention is affective in nature. In this study, we argue that prospective employees' trust in a company should be related to their job-seeking intentions. The reasoning for our claim was based on the notion that cognitive constructs can influence affective constructs [30]. This line of reasoning is also obvious when viewed from the perspective of social identity theory, which posits that individuals who have trust in a group or an organization seek to gain social identity by engaging in that group or organization. Given that applicants' trust in a firm influences their decisions to accept or refuse jobs offered by the firm [19], it is reasonable to expect that prospective employees' trust in an organization should be associated with their job-seeking intentions. Based on these considerations, we proposed the following hypothesis:

Hypothesis 5 (H5). Organizational trust positively affects job-seeking intentions.

\subsection{Sequential Mediating Mechanism of Organizational Trust and Job-Seeking Attitudes}

In a recent review study, Pham and Paillé [31] highlighted the intervening factors influencing job seekers' attraction to an organization, suggesting a multistage underlying psychological process that predicts prospective employees' job-seeking intentions. The theoretical arguments of this paper so far suggest that applicants' positive perceptions about a firm's CER activities improve their trust in the firm, which in turn affects their job-seeking attitudes that eventually lead to higher job-seeking intentions. Hence, it is meaningful to investigate the indirect effects of CER perceptions on job-seeking intentions through the chain influence of organizational trust and job-seeking attitudes in the proposed research model [32]. Another rationale for testing the sequential mediating effect is that if it is hypothesized that $A$ leads to $B, B$ leads to $C$, and $C$ leads to $D$, then the impact of $A$ on $D$ through the serial influence of $B$ and $C$ should be significant [33]. This reasoning is also common in other fields of studies (e.g., [32]). When applied to the present research model, 
it seems reasonable to examine the serial mediation so as to accurately understand how CER perceptions can influence job-seeking intentions. Therefore, we came up with the following hypothesis:

Hypothesis 6 (H6). Organizational trust and job-seeking attitudes sequentially mediate the effects of CER perceptions on job-seeking intentions.

In addition, we expected that the test of hypothesis $\mathrm{H} 6$ would be a partially mediated one because a substantial body of empirical research (e.g., [17,34]) demonstrated a strong association of job seekers' perceptions about a firm's environmental efforts with their job-seeking intentions through other psychological variables (such as perceived value fit, corporate image, and reputation) that were not considered in the present study. Therefore, we proposed and examined Hypothesis $\mathrm{H} 7$ to replicate the past research findings as an essential complement to the research model under consideration in this study.

Hypothesis 7 (H7). CER perceptions positively affect job-seeking intentions.

\section{Materials and Methods}

\subsection{Participants and Procedure}

To test the research hypotheses empirically, a self-administered questionnaire was developed to collect data from final-year undergraduate and graduate students enrolled in public universities in Bangladesh. A pilot study with a convenient sample of 20 respondents was conducted to assess the understandability of the measurement items. The measures seemed to be usable in the context of the study. After the pilot test, an online survey questionnaire link was sent to the respective class coordinators asking them to forward the link to the students to fill in the form. A list of 20 companies selected based on the top 20 shares reported by the Dhaka Stock Exchange (the largest stock market in the country) was included for reference in the early part of the questionnaire. Those 20 companies belonged to a wide range of industries such as telecommunication, government bodies, financial and nonfinancial, multinationals, health care, NGOs, and service. Respondents were first asked to select one of those companies with which they were most familiar and then to indicate their level of agreement with the statements of the survey questionnaire. A total of 381 respondents participated in the survey.

During the data-cleaning process, 24 respondents were found to be unengaged (i.e., the standard deviation of their answers to all the statements was found to be zero) while they filled in the questionnaire; hence, their observations were not considered in the analysis to avoid confounding results. For social science research, the remaining sample size (i.e., $\mathrm{n}=357$ ) was suitable for structural equation modeling for the focal 4 constructs of the study [35]. Most of the participants were male (58\%), 23 years of age (22.7\%), and undergraduate students $(72.3 \%)$. It is important to note that the target sample was an appropriate research subject for the present study because many firms in the labor market of the country consider final-year students as their potential human resources for entrylevel jobs. The social-cultural context of the country is formed in such a way that most university students prefer to seek employment in an organization rather than to become entrepreneurs [36]. Another rationale for selecting final-year students was that employer choice is a vital issue they need to face right before their graduation and, hence, they were very concerned about the job market and the potential employers [37].

\subsection{Measures}

The measurement items used to examine the focal 4 constructs of the study were selected based on the previous studies. Unless otherwise indicated, participants were asked to indicate the extent to which they agree or disagree with the statements provided in the questionnaire. Statements were graded on a 5-point Likert scale, with 1 indicating strong disagreement and 5 indicating strong agreement. For every case, a higher score 
referred to the higher level of a construct. A brief description of the selected measurement items for each construct of our study is as follows:

\subsubsection{CER Perceptions}

Respondents' perceived CER was measured using 5 items tailored from Alcañiz et al. [38]. A sample item of CER perceptions was: "It appears that the organization participates in activities that aim to protect the natural environment". The reliability estimate of this construct in our study was 0.84 .

\subsubsection{Job-Seeking Intentions}

This construct was measured using 4 items selected and adapted from Vinkor and Caplan [39] and Huang [40]. One of the four items used was: "I really intend to try hard to search for jobs in the organization as soon as possible". The reliability coefficient of job-seeking intentions for the study was 0.77 .

\subsubsection{Job-Seeking Attitudes}

Respondents' attitudes toward job-seeking were assessed using 4 items adapted from Taylor and Todd [41]. One of the items included was: "I think searching for jobs in the organization is good for me". Cronbach's alpha for respondents' job-seeking attitudes was 0.75 .

\subsubsection{Organizational Trust}

Respondents' trust in an organization was measured using 5 items selected and adapted from Dhanesh [42]. A representative item of job seekers' organizational trust was: "I believe that the organization treats people like me fairly and justly". The reliability measure of this construct was 0.80 .

\subsubsection{Control Variables}

Additionally, respondents' demographic information was taken into consideration as control variables of the present study. Respondents' gender, age, and education status were controlled for analysis because they were reported to be influential on job-seeking intentions in previous studies (e.g., [43,44]).

\subsection{Overview of Analyses}

Analyses were conducted in three consecutive steps. First, reliability, validity, multicollinearity, and common method bias (CMB) of the constructs were measured using exploratory factor analysis (EFA) and confirmatory factor analysis (CFA) simultaneously. Second, well-established fit indices were taken into consideration to examine whether the measurement model and the structural model represented the data well. Finally, standardized path coefficients of the full structural model were considered to test the research hypotheses of this study. All the research hypotheses were tested using path analysis with AMOS (version 24), a structural equation modeling (SEM) program. In addition, to check the robustness of the sequential mediating effect of organizational trust and job-seeking attitudes, Hayes's [33] PROCESS Macro (version 3.4) was used because it is being considered as a more powerful statistical tool for probing mediation.

\section{Results}

\subsection{Test of Reliability, Validity, Multicollinearity, and CMB}

EFA was conducted to examine whether the items represented a clean factor structure. A principal component analysis with varimax rotation extracted 4 factors with eigenvalues greater than 1 . Of the 18 scale items, 14 were loaded on the hypothesized factors as per our expectation. However, 2 items were below the threshold loadings of 0.40 , and 2 items were significantly cross-loaded. Therefore, 4 items were not considered for further analysis to avoid misleading results [45]. Cronbach's alpha $(\alpha)$ and composite reliability (CR) 
were taken into consideration to measure the construct reliability. CR for each construct ranged from 0.752 to 0.852 , exceeding the established threshold of 0.70 (shown in Table 1 ). The average variance extracted (AVE) and the factor loadings of the items were taken into account to measure the convergent validity. The AVE values ranged from 0.503 to 0.644 , ensuring the convergent validity of the study constructs [46]. The factor loadings of the measurement items ranged from 0.571 to 0.875 , and were statistically significant $(p<0.001)$. Harman's single-factor test indicated that CMB was not a major concern for this study (the single factor accounted for 30.56\%) [47]. The collinearity statistics in Table 1 show that multicollinearity did not exist, as the variance inflation factors (VIF) did not exceed the threshold of 10 , and tolerance values were above the threshold of 0.10 [35].

The discriminant validity of the constructs was assessed based on the suggestions of Fornell and Larcker [46]. As shown in Table 2, the square root of each construct's AVE was higher than the respective interconstruct correlation, indicating support for the discriminant validity of all the constructs. In addition, Table 1 shows that the maximum shared variance (MSV) for each construct was lower than the AVE of the respective construct, signifying further support for the discriminant validity [35]. In summary, all these results clearly indicated that the instruments used for measuring the focal 4 constructs in the study were statistically suitable. After ensuring the reliability and validity of the measurement model, established fit indices such as Chi-square $\left(\chi^{2}\right)$, the ratio of $\chi^{2}$ to the degree of freedom $\left(\chi^{2} / d f\right)$, comparative fit index (CFI), the root mean square error of approximation (RMSEA), the standardized root mean square residual (SRMR), and $p$ of close fit (PCLOSE) were taken into consideration to determine whether the measurement model represented the data well. The fit statistics revealed that the four-factor measurement model fit the data well in comparison to the one-factor model (shown in Table 3), thus demonstrating further support for discriminant validity [40].

\subsection{Test of Structural Model}

Given that our measurement model fit the data well, structural relationships among the latent constructs were added to test the efficacy of our hypothesized research model. Control variables were also considered in the structural model. Before testing the research hypotheses, we conducted alternative model comparison tests to determine which model represented our data well following the procedure of Huang [40]. As the $\chi^{2}$ statistics were sensitive to sample size [49], a similar set of fit indices was taken into consideration to examine the fit of the nested alternative structural models. Table 4 reports the results of nested model comparisons. The results showed that all the fit indices (i.e., $\chi^{2} / d f=1.93, \mathrm{CFI}=0.988, \mathrm{SRMR}=0.037, \mathrm{RMSEA}$ $=0.051$, PCLOSE $=0.423$ ) of our hypothesized research model were better than those of any of the eight other alternative models (shown in Table 4). Therefore, we selected our hypothesized model as the final research model to test the research hypotheses.

\subsection{Hypothesis Testing}

The standardized path coefficient $(\beta)$ was taken into consideration to test the hypotheses regarding the direct relationship among the constructs of the present study. The structural model explained $31 \%$ of the variance $\left(R^{2}\right)$ in job-seeking intentions, indicating the acceptable explanatory power of the model. As depicted in Figure 2, five out of six hypotheses regarding the direct relationship between the constructs were found to be significant, thus providing support for Hypotheses H1, H2, H3, H4, and H7 (shown in Table 5). Despite the significant positive correlations between organizational trust and job-seeking intentions (shown in Table 2), when analyzed together with other constructs of the present study in the structural model, the organizational trust did not significantly predict job-seeking intentions, providing no support for Hypothesis H5. 
Table 1. Reliability and validity statistics.

\begin{tabular}{|c|c|c|c|c|c|c|c|}
\hline \multirow{2}{*}{$\begin{array}{l}\text { Constructs } \\
\text { and Items }\end{array}$} & \multirow{2}{*}{ CFA Loadings } & \multirow{2}{*}{ CR } & \multirow{2}{*}{ AVE } & \multirow{2}{*}{ MSV } & \multirow{2}{*}{ Cronbach's $(\alpha)$} & \multicolumn{2}{|c|}{ Multicollinearity } \\
\hline & & & & & & Tolerance & VIF \\
\hline $\begin{array}{c}\text { CER } \\
\text { Perceptions }\end{array}$ & & 0.852 & 0.542 & 0.244 & 0.843 & 0.791 & 1.264 \\
\hline CER5 & 0.800 & & & & & & \\
\hline CER4 & 0.624 & & & & & & \\
\hline CER3 & 0.836 & & & & & & \\
\hline CER2 & 0.809 & & & & & & \\
\hline CER1 & 0.571 & & & & & & \\
\hline $\begin{array}{c}\text { Organizational } \\
\text { trust }\end{array}$ & & 0.801 & 0.503 & 0.244 & 0.798 & 0.789 & 1.267 \\
\hline OT5 & 0.686 & & & & & & \\
\hline OT4 & 0.750 & & & & & & \\
\hline OT2 & 0.746 & & & & & & \\
\hline OT1 & 0.670 & & & & & & \\
\hline $\begin{array}{l}\text { Job-seeking } \\
\text { attitudes }\end{array}$ & & 0.752 & 0.503 & 0.384 & 0.752 & 0.870 & 1.149 \\
\hline ATT4 & 0.688 & & & & & & \\
\hline ATT3 & 0.726 & & & & & & \\
\hline ATT1 & 0.714 & & & & & & \\
\hline $\begin{array}{c}\text { Job-seeking } \\
\text { intentions }\end{array}$ & & 0.782 & 0.644 & 0.384 & 0.773 & & \\
\hline INT2 & 0.722 & & & & & & \\
\hline INT1 & 0.875 & & & & & & \\
\hline
\end{tabular}

Notes: All CFA loadings were significant at $* * * p<0.001$. CER $=$ corporate environmental responsibility perceptions; OT $=$ organizational trust; ATT = job-seeking attitudes; INT = job-seeking intentions. As mentioned earlier, items INT3, INT4, ATT2, and OT3 were not considered for final analysis.

Table 2. Means, standard deviations, and correlations among the variables.

\begin{tabular}{|c|c|c|c|c|c|c|c|c|c|}
\hline Variables & $\mathbf{M}$ & SD & 1 & 2 & 3 & 4 & 5 & 6 & 7 \\
\hline 1. Gender ${ }^{a}$ & 0.420 & 0.494 & 1 & & & & & & \\
\hline 2. Age $\mathrm{b}^{\mathrm{b}}$ & 22.753 & 1.762 & $-0.245^{* *}$ & 1 & & & & & \\
\hline 3. Education ${ }^{c}$ & 0.280 & 0.448 & $-0.185^{* *}$ & $0.666^{* *}$ & 1 & & & & \\
\hline 4. ATT & 3.770 & 0.603 & -0.025 & -0.039 & 0.068 & $(0.709)$ & & & \\
\hline 5. INT & 3.951 & 0.631 & $-0.105 *$ & $0.147^{* *}$ & $0.120 *$ & 0.466 ** & $(0.802)$ & & \\
\hline 6. CER & 4.042 & 0.633 & -0.081 & $0.178^{\text {** }}$ & $0.174^{* *}$ & 0.302 ** & $0.333^{* *}$ & $(0.736)$ & \\
\hline 7. OT & 3.833 & 0.601 & 0.006 & -0.024 & -0.002 & $0.306^{* *}$ & $0.277^{* *}$ & $0.419 * *$ & $(0.709)$ \\
\hline
\end{tabular}

Notes: ${ }^{\text {a }} 0=$ Male, $1=$ Female; $^{\mathrm{b}}=$ Age in years; ${ }^{\mathrm{c}} 0=$ Undergraduate, $1=$ Graduate. ${ }^{* *}$ Correlation was significant at the 0.01 level (2-tailed).

${ }^{*}$ Correlation was significant at the 0.05 level (2-tailed). $n=357$. Values in the brackets are the square root of the AVE of the respective construct.

Table 3. Fit indices of measurement model and structural model.

\begin{tabular}{|c|c|c|c|}
\hline Model Fit Index & $\begin{array}{l}\text { Measurement } \\
\text { Model }\end{array}$ & $\begin{array}{l}\text { Structural } \\
\text { Model }\end{array}$ & Cutoff Criteria \\
\hline Chi-square $\left(\chi^{2}\right)$ & 121.063 & 11.581 & \\
\hline Degree of freedom $(d f)$ & 71 & 6 & \\
\hline The ratio of $\chi^{2}$ to $d f\left(\chi^{2} / d f\right)$ & 1.705 & 1.930 & $\leq 3[48]$ \\
\hline CFI & 0.973 & 0.988 & $\geq 0.90[48]$ \\
\hline SRMR & 0.040 & 0.037 & $\leq 0.08[48]$ \\
\hline RMSEA & 0.045 & 0.051 & $\leq 0.08[48]$ \\
\hline PCLOSE & 0.738 & 0.423 & $\geq 0.05[48]$ \\
\hline
\end{tabular}

Notes: Fit statistics for one-factor measurement model: $\chi^{2} / d f=10.083, \mathrm{CFI}=0.625, \mathrm{SRMR}=0.131, \mathrm{RMSEA}=0.160$, PCLOSE $=0.000$. 
Table 4. Comparison of alternative models against the research model.

\begin{tabular}{|c|c|c|c|c|c|c|c|c|c|}
\hline \multirow{2}{*}{ Fit Indices } & \multirow{2}{*}{$\begin{array}{c}\text { Research } \\
\text { Model }\end{array}$} & \multicolumn{8}{|c|}{ Alternative Models } \\
\hline & & 1 & 2 & 3 & 4 & 5 & 6 & 7 & 8 \\
\hline$\chi^{2}$ & 11.581 & 80.207 & 26.268 & 19.576 & 27.16 & 15.237 & 73.782 & 29.925 & 44.151 \\
\hline$d f$ & 6 & 7 & 7 & 7 & 7 & 7 & 7 & 8 & 9 \\
\hline$\chi^{2} / d f$ & 1.93 & 11.458 & 3.753 & 2.797 & 3.88 & 2.177 & 10.54 & 3.741 & 4.906 \\
\hline CFI & 0.988 & 0.845 & 0.959 & 0.973 & 0.957 & 0.983 & 0.859 & 0.954 & 0.926 \\
\hline SRMR & 0.037 & 0.101 & 0.053 & 0.045 & 0.055 & 0.039 & 0.081 & 0.055 & 0.078 \\
\hline RMSEA & 0.051 & 0.171 & 0.088 & 0.071 & 0.090 & 0.057 & 0.164 & 0.088 & 0.105 \\
\hline PCLOSE & 0.423 & 0 & 0.036 & 0.151 & 0.029 & 0.327 & 0 & 0.028 & 0.002 \\
\hline \multicolumn{4}{|c|}{$\begin{array}{c}\text { Notes: } \\
\text { Model 1. CER } \rightarrow \text { OT was fixed }\end{array}$} & \multicolumn{6}{|c|}{ Model 5: OT $\rightarrow$ INT was fixed to 0} \\
\hline \multicolumn{4}{|c|}{ Model 2: CER $\rightarrow$ ATT was fixed to 0} & \\
\hline \multicolumn{4}{|c|}{ Model 3: CER $\rightarrow$ INT was fixed to 0} & \multicolumn{6}{|c|}{ Model 7: CER $\rightarrow$ ATT, and OT $\rightarrow$ INT were fixed to 0} \\
\hline \multicolumn{4}{|c|}{ Model 4: OT $\rightarrow$ ATT was fixed to 0} & \multicolumn{6}{|c|}{ Model 8: Full mediation (CER $\rightarrow$ ATT, OT $\rightarrow$ INT, and CER $\rightarrow$ INT were fixed to 0 ) } \\
\hline
\end{tabular}

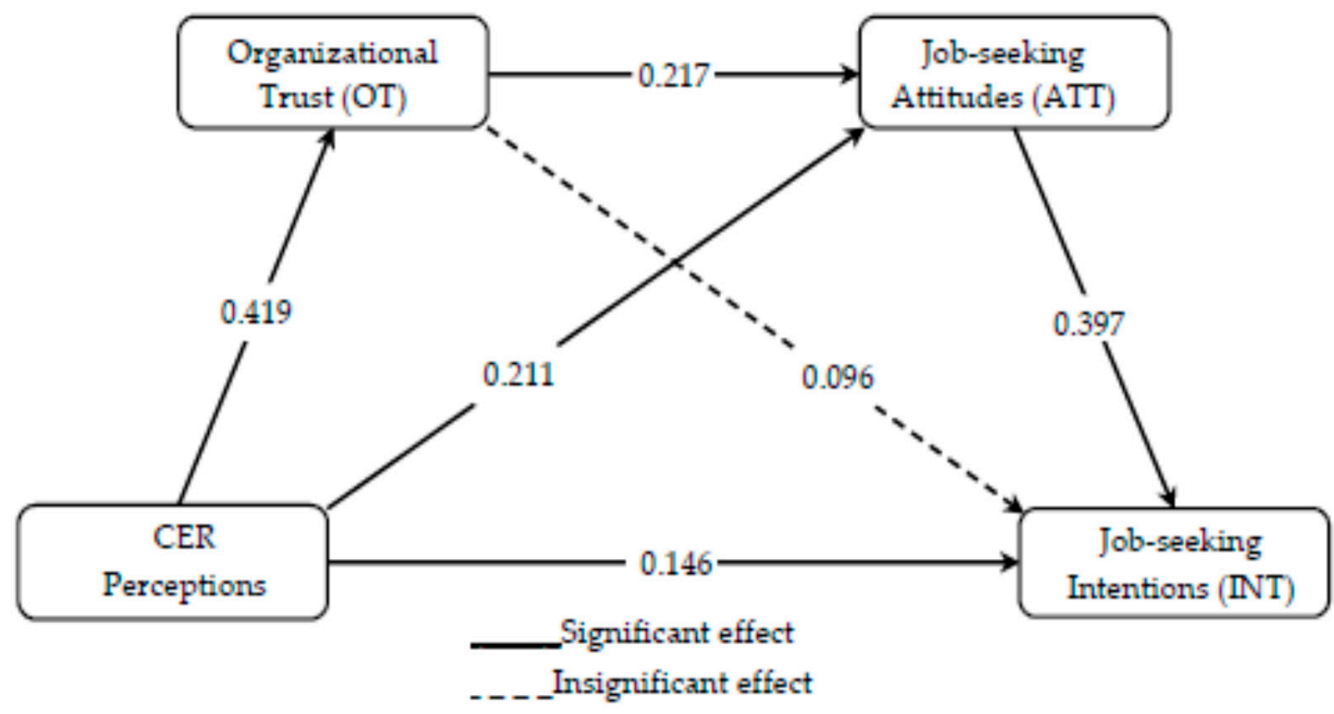

Figure 2. Standardized path coefficients.

Table 5. Summary results of hypotheses testing.

\begin{tabular}{|c|c|c|c|c|c|c|c|}
\hline $\begin{array}{l}\text { Hypothesis } \\
\text { No. }\end{array}$ & Path & $\begin{array}{l}\text { Direct } \\
\text { Effects }\end{array}$ & $\begin{array}{l}\text { Indirect } \\
\text { Effects }\end{array}$ & SE & $p$ & $\begin{array}{l}95 \% \text { CI } \\
\text { (Low, } \\
\text { High) }\end{array}$ & $\begin{array}{l}\text { Hypothesis (Sup- } \\
\text { ported/Rejected) }\end{array}$ \\
\hline H1 & $\mathrm{CER} \rightarrow \mathrm{OT}$ & 0.419 & & 0.046 & $<0.001$ & & Supported \\
\hline $\mathrm{H} 2$ & $\mathrm{CER} \rightarrow \mathrm{ATT}$ & 0.211 & & 0.052 & $<0.001$ & & Supported \\
\hline H3 & $\mathrm{OT} \rightarrow \mathrm{ATT}$ & 0.217 & & 0.054 & $<0.001$ & & Supported \\
\hline $\mathrm{H} 4$ & $\mathrm{ATT} \rightarrow \mathrm{INT}$ & 0.397 & & 0.051 & $<0.001$ & & Supported \\
\hline H5 & $\mathrm{OT} \rightarrow \mathrm{INT}$ & 0.096 & & 0.053 & $>0.05$ & & Rejected \\
\hline H6 & $\begin{array}{c}\mathrm{CER} \rightarrow \text { OT } \\
\rightarrow \text { ATT } \rightarrow \\
\quad \text { INT }\end{array}$ & & 0.037 & 0.016 & & $\begin{array}{l}(0.012, \\
0.073)\end{array}$ & Supported \\
\hline $\mathrm{H} 7$ & $\mathrm{CER} \rightarrow \mathrm{INT}$ & 0.146 & & 0.052 & $<0.01$ & & Supported \\
\hline
\end{tabular}

To test the sequential mediation hypothesis, we directly examined the significance of indirect effects of CER perceptions on job-seeking intentions through serial multiple mediators [32,33]. We analyzed the data with 5000 bootstrap samples of $95 \%$ bias-corrected confidence intervals (CI) using Model 6, as recommended in Hayes's [33] PROCESS Macro. Hypothesis H6 stated that the indirect effect of perceived CER on job-seeking intentions 
through the sequential influence of organizational trust and job-seeking attitudes is significant. As shown in Table 5, the results of the analysis indicated that CER perception was positively associated first with organizational trust and then job-seeking attitudes, which was positively related to job-seeking intentions. Furthermore, the direct effect of CER perceptions on job-seeking intentions was also found to be significant. In sum, we confirmed that the direct relationship between CER perceptions and job-seeking intentions was partially and sequentially mediated by organizational trust and job-seeking attitudes, thus providing support for Hypothesis H6.

\section{Discussion}

Researchers called for exploring the role of job seekers' organizational trust in the early stage of recruitment [50]. In addition, there is limited research that empirically examined the role of CER perceptions in predicting applicants' job-seeking intentions. Despite the plausible roles of organizational trust and job-seeking attitudes in the relationship between CER perceptions and job-seeking intentions, empirical research on this theoretical phenomenon is still unavailable in job-seeking literature. This study empirically examined how prospective employees' CER perceptions directly and indirectly affect their job-seeking intentions. More specifically, this study attempted to extend past studies by building a critical bridge between prospective employees' CER perceptions and their job-seeking intentions through exploring the sequential mediating mechanism of organizational trust and job-seeking attitudes.

The study findings were consistent with previous research that demonstrated a strong association of CER perceptions and job-seeking attitudes with job-seeking intentions (e.g., $[25,28])$. However, this study also made some additional contributions to the existing job-seeking literature. This study confirmed that prospective employees use signals from a firm's CER efforts to form their organizational trust, which, in turn, leads to their job-seeking attitudes that eventually result in their job-seeking intentions. Noticeably, while job-seeking attitudes significantly influenced job-seeking intentions, organizational trust could not predict job-seeking intentions within the research model. However, organizational trust and job-seeking attitudes together sequentially and partially mediated the impact of CER perceptions on job-seeking intentions, suggesting that prospective employees' CER perceptions were robust for predicting job-seeking intentions both directly and indirectly within our research model.

One possible reason for why organizational trust could not significantly influence job-seeking intentions within the research model may be due to the number of items, which might have resulted in less variability in the outcome. However, it is noteworthy that when we excluded job-seeking attitudinal construct from the model, organizational trust was found to have a significant influence on job-seeking intentions $(\beta=0.181, p<0.01)$, and the indirect effect of CER perceptions on job-seeking intentions via organizational trust was also found to be significant $(\beta=0.076, p<0.01)$. Therefore, this indicates that job-seeking attitudes caused the insignificant association of organizational trust with jobseeking intentions within our research model. Besides this, the use of organizational trust and job-seeking attitudes in the relationship between CER perceptions and job-seeking intentions also gave further insights into the dynamic existence of the associations among the study variables.

\subsection{Theoretical Contributions}

This study contributes to the growing body of knowledge on job-seeking literature in the following ways. First, this study confirmed the underlying mechanisms through which CER perceptions shape applicant attraction to an organization. Although past studies demonstrated the effects of organizational trust and job-seeking attitudes on jobseeking intentions separately, none of those studies considered them to explain the linkage of CER perceptions with job-seeking intentions in a single framework. This research demonstrated how CER perceptions shape prospective employees' job-seeking intentions 
through more proximal outcomes of organizational trust and job-seeking attitudes in sequence. By presenting empirical evidence on the sequential mediating process, this paper is an important step forward for further research on such mechanisms, via which CER perceptions can predict prospective applicants' job-seeking intentions.

Second, an important finding of the study was that organizational trust could only predict job-seeking intentions through the influence of job-seeking attitudes, confirming the argument that any variables external to the TPB model can only predict a person's behavioral intentions indirectly through any one of the TPB core variables (i.e., job-seeking attitudes in the study) [51]. However, contrary to the argument, CER perceptions (as an external variable to the TPB) could also directly predict job-seeking intentions within our research model. This difference in findings advances the understanding of the complexity of sequential mediation through which CER perceptions influence job-seeking intentions, providing an important foundation for further research into the job-seeking process of prospective employees.

Third, by integrating social theories into a single framework, this study demonstrated the understanding of how psychological factors can together explain the relationship between CER perceptions and prospective applicants' job-seeking intentions. By identifying the serial mediating roles of organizational trust and job-seeking attitudes, this study contributes to the theoretical development of job-seeking literature that until now has not evidently provided clear paths from CER perceptions to job-seeking intentions. Further, while most past studies were focused too heavily on Western society, little is known about the job-seeking process of potential applicants in developing countries, even less so in the context of Bangladesh. Therefore, the present study adds value to the existing job search literature and is an important step forward in examining the generalizability of the research findings.

\subsection{Managerial Implications}

This study also suggested some practical implications for HR professionals in today's organizations. First, millennials are not merely influenced by the benefits, awards, and compensation that jobs offer to them. Rather, given that individuals' behaviors are based on their perceptions of what reality is [52], HR managers, along with the other hard factors such as competitive compensation and benefits, should concern themselves with job seekers' perceptions about a firm's CER activities. It would be wise if HR managers fully understand how prospective employees perceive and respond to organizational CER activities. It is expected that firms develop and implement plans and policies to minimize the potential negative effects of their operational activities on the natural environment; however, during the recruitment campaign, it might be more important for a firm to communicate its CER efforts with potential applicants to influence their job-seeking intentions. It is therefore advisable that HR professionals should communicate their CER activities to improve prospective employees' job-seeking intentions.

Second, it would be a mistake to consider a firm's CER as the only direct antecedent of people's job-seeking intentions. To remain competitive in the marketplace, firms need to develop trust among the potential applicants, and engaging in environmental activities is likely to provide such distinctness. According to the findings of the study, job seekers' organizational trust determined by their perceived CER activities tended to influence their job-seeking attitudes, which could be effectively used as a key checkpoint for improving their intentions to search for jobs in the organization. Therefore, during a firm's recruitment campaign, providing realistic information about its participation in and awards for CER and other sustainability activities might contribute to shape prospective employees' trust in the firm. HR professionals may consider corporate websites, recruitment channels, or other social-media platforms to communicate their CER activities to potential human resources.

Third, if a firm communicates its CER activities with potential job seekers during its recruitment campaign, such activities may become more effective, as the study demonstrated organizational trust as one of the outcomes of applicants' CER perceptions. In addition, 
our work confirmed that job-seeking attitude is directly affected by organizational trust and CER perceptions. This understanding of mechanisms via which CER perceptions influence recruitment outcomes will likely provide HR professionals with insights on framing effective recruitment strategies to achieve expected long-term outcomes. Furthermore, the direct roles of CER perceptions and job-seeking attitudes in predicting job-seeking intentions are theoretically and practically justifiable, because people's job-search intentions are unlikely to be improved if they perceive low CER efforts of a firm [25] and have negative emotional thoughts about searching for jobs in the organization [53].

All in all, the significant direct and indirect effects of CER perceptions on job-seeking intentions through serial mediators suggest a dual-track approach to attract prospective employees to an organization. Given that people's job-seeking intentions cannot be arbitrarily improved by the proximal recruitment campaigns [37], it can be boosted in the long term if job seekers perceive an organization as environmentally responsible. Because of the "war for talent", attracting high-quality applicants is one of the major critical tasks for HR professionals [54], and has become a major antecedent for gaining competitive advantages [55]. Hence, the implications of our research findings are significant.

\subsection{Limitations and Future Research Directions}

This study had three drawbacks associated with the interpretation of the empirical findings. First, our research model considered job-seeking intentions as the ultimate dependent variable of CER perceptions. Given that people's intentions to behave may not be always transformed into actual behavior [56], the inclusion of actual behavioral construct might produce different outcomes. Therefore, within our research model, future researchers may consider actual job-seeking behaviors as the ultimate dependent variable in order to explore the relative influence of job seekers' CER perceptions in greater depth.

Second, as noted before, a list of companies was provided in the first part of the questionnaire, and respondents were first asked to select one of those companies with which they were most familiar. However, organizational familiarity was not measured and controlled in this study, indicating another limitation. Furthermore, considering the purpose of the study, we did not address respondents' other subjective factors (such as salaries and benefits, self-efficacy, normative pressures, etc.) that were found to be influential in predicting job-seeking intentions in past studies (e.g., $[57,58])$. Therefore, future research may consider these issues to yield more vigorous findings suitable for generalization.

Finally, this study adopted a cross-sectional design to collect data from undergraduate and graduate students in one country at a single point in time with a self-administered questionnaire, which limited the generalizability of the research findings [47]. In addition, the antecedents of job-search intentions for actual job seekers may be different from those of graduating students. This study provided a fairly homogeneous sample of the respondents, thus minimizing the possibility of confounding results [59]. However, readers must be cautious when generalizing this study's findings. Therefore, future research may consider a longitudinal design targeting actual job seekers from various countries with different cultural backgrounds to produce more robust results.

Author Contributions: All the authors together developed the theoretical model and research hypotheses, collected data, performed statistical analyses, were involved in the interpretation of the findings, and drafted the manuscript. All authors have read and agreed to the published version of the manuscript.

Funding: This research received no external funding.

Institutional Review Board Statement: Ethical review and approval were waived for this study, due to the lack of sensitive data and the anonymization of all personal information of the people engaged in the study.

Informed Consent Statement: Informed consent was obtained from all subjects involved in the study. 
Data Availability Statement: The data sets used in this study are available from the corresponding author on reasonable request.

Acknowledgments: This work was supported by a research grant from Inha University. The authors are grateful for the support of this work. The authors are also thankful to the editors and three anonymous reviewers for their valuable comments and suggestions to improve the quality of the manuscript.

Conflicts of Interest: The authors declare no conflict of interest.

\section{References}

1. Hoang, L.V.; Vu, H.M.; Ngo, V.M. Corporate social responsibility and job pursuit intention of employees in Vietnam. J. Asian Financ. Econ. Bus. 2020, 7, 345-353. [CrossRef]

2. Lis, B. Corporate social responsibility's influence on organizational attractiveness: An investigation in the context of employer choice. J. Gen. Manag. 2018, 43, 106-114. [CrossRef]

3. Loes, C.N.; Tobin, M.B. Organizational trust, psychological empowerment, and organizational commitment among licensed practical nurses. Nurs. Adm. Q. 2020, 44, 179-187. [CrossRef] [PubMed]

4. Kadarusman, K.; Bunyamin, B. The role of knowledge sharing, trust as mediation on servant leadership and job performance. Manag. Sci. Lett. 2021, 11, 1509-1520. [CrossRef]

5. Kim, S.E.; Lee, S.H. Perceptions of social performance in public enterprises and early job seekers' intentions to apply. Int. Rev. Public Adm. 2020, 1-16. [CrossRef]

6. Jung, Y.; Takeuchi, N.; Takeuchi, T. Understanding psychological processes of applicants' job search. Evid.-Based HRM 2016, 4, 190-213. [CrossRef]

7. Hanson-Rasmussen, N.; Lauver, K.J. Do students view environmental sustainability as important in their job search? Differences and similarities across culture. Int. J. Environ. Sustain. Dev. 2017, 16, 80-98. [CrossRef]

8. Barber, A.E. Recruiting Employees: Individual and Organizational Perspectives; SAGE: Thousand Oaks, CA, USA, 1998; ISBN 9780761909439.

9. Dineen, B.R.; Soltis, S.M. Recruitment: A review of research and emerging directions. In APA Handbook of Industrial and Organizational Psychology; Zedeck, S., Ed.; American Psychological Association: Washington, DC, USA, 2011; pp. 43-66.

10. Chaudhary, R. Green human resource management and job pursuit intention: Examining the underlying processes. Corp. Soc. Responsib. Environ. Manag. 2019, 26, 929-937. [CrossRef]

11. Li, Z.; Liao, G.; Albitar, K. Does corporate environmental responsibility engagement affect firm value? The mediating role of corporate innovation. Bus. Strateg. Environ. 2020, 29, 1045-1055. [CrossRef]

12. Omisore, A.G.; Babarinde, G.M.; Bakare, D.P.; Asekun-Olarinmoye, E.O. Awareness and knowledge of the sustainable development goals in a University Community in Southwestern Nigeria. Ethiop. J. Health Sci. 2017, 27, 669. [CrossRef]

13. Islam, M.A.; Hunt, A.; Jantan, A.H.; Hashim, H.; Chong, C.W. Exploring challenges and solutions in applying green human resource management practices for the sustainable workplace in the ready-made garment industry in Bangladesh. Bus. Strateg. Dev. 2020, 3, 332-343. [CrossRef]

14. Ruepert, A.M.; Keizer, K.; Steg, L. The relationship between corporate environmental responsibility, employees' biospheric values and pro-environmental behaviour at work. J. Environ. Psychol. 2017, 54, 65-78. [CrossRef]

15. Torelli, R.; Balluchi, F.; Lazzini, A. Greenwashing and environmental communication: Effects on stakeholders' perceptions. Bus. Strateg. Environ. 2020, 29, 407-421. [CrossRef]

16. Hanson-Rasmussen, N.; Lauver, K.; Lester, S. Business student perceptions of environmental sustainability: Examining the job search implications. J. Manag. Issues 2014, 26, 174-193.

17. Carballo-Penela, A.; Ruzo-Sanmartín, E.; Sousa, C.M.P. Influence of business commitment to sustainability, perceived value fit, and gender in job seekers' pursuit intentions: A cross-country moderated mediation analysis. Sustainability 2020, $12,4395$. [CrossRef]

18. Mayer, R.C.; Davis, J.H.; Schoorman, F.D. An integrative model of organizational trust. Acad. Manag. Rev. 1995, 20, 709-734. [CrossRef]

19. Kedharnath, U.; Shore, L.M.; Dulebohn, J.H. Organizational trust among job seekers: The role of information-seeking and reciprocation wariness. Int. J. Sel. Assess. 2020, 28, 351-363. [CrossRef]

20. Brown, T.J.; Dacin, P.A. The company and the product: Corporate associations and consumer product responses. J. Mark. 1997, 61, 68-84. [CrossRef]

21. Pivato, S.; Misani, N.; Tencati, A. The impact of corporate social responsibility on consumer trust: The case of organic food. Bus. Ethics A Eur. Rev. 2007, 17, 3-12. [CrossRef]

22. Spence, M. Job market signaling. Q. J. Econ. 1973, 87, 355-374. [CrossRef]

23. Ajzen, I. The theory of planned behavior. Organ. Behav. Hum. Decis. Process. 1991, 50, 179-211. [CrossRef]

24. Carmack, H.J.; Heiss, S.N. Using the theory of planned behavior to predict college students' intent to use linkedIn for job searches and professional networking. Commun. Stud. 2018, 69, 145-160. [CrossRef] 
25. Moorthy, K.; Na, A.S.; Yee, W.C.; Xian, Y.C.; Jin, T.O.; Mun, S.T.; Shan, S.W. Influence of corporate social responsibility in job pursuit intention among prospective employees in Malaysia. Int. J. Law Manag. 2017, 59, 1159-1180. [CrossRef]

26. Hogg, M.A. Social identity theory. In Understanding Peace and Conflict Through Social Identity Theory; McKeown, S., Haji, R., Neil, F., Eds.; Springer: Cham, Switzerland, 2016; ISBN 978-3-319-29869-6.

27. Georgiou, K.; Nikolaou, I.; Tomprou, M.; Rafailidou, M. The role of job seekers' individual characteristics on job seeking behavior and psychological well-being. Int. J. Sel. Assess. 2012, 20, 414-422. [CrossRef]

28. Yizhong, X.; Lin, Z.; Baranchenko, Y.; Lau, C.K.; Yukhanaev, A.; Lu, H. Employability and job search behavior: A six-wave longitudinal study of Chinese university graduates. Empl. Relat. 2017, 39, 223-239. [CrossRef]

29. Leenders, M.V.E.; Buunk, A.P.; Henkens, K. Attachment avoidance and attachment anxiety as individual characteristics affecting job search behavior. J. Career Dev. 2019, 46, 487-501. [CrossRef]

30. Fishbein, M.; Ajzen, I. Belief, Attitude, Intention, and Behavior: An Introduction to Theory and Research; Addison-Wesley: Reading, MA, USA, 1975; ISBN 0201020890.

31. Pham, D.D.T.; Paillé, P. Green recruitment and selection: An insight into green patterns. Int. J. Manpow. 2019, 41, 258-272 [CrossRef]

32. Shin, I.; Hur, W.M.; Kang, S. Employees' perceptions of corporate social responsibility and job performance: A sequential mediation model. Sustainability 2016, 8, 493. [CrossRef]

33. Hayes, A.F. Introduction to Mediation, Moderation and Conditional Process Analysis: A Regression-Based Approach, 2nd ed.; The Guilford Press: New York, NY, USA, 2018; ISBN 9781462534654.

34. Chaudhary, R. Can green human resource management attract young talent? An empirical analysis. Evid.-Based HRM 2018, 6, 305-319. [CrossRef]

35. Hair, J.F.; Black, W.C.; Babin, B.J.; Anderson, R.E. Multivariate Data Analysis, 7th ed.; Prentice Hall: Upper Saddle River, NJ, USA, 2009; ISBN 0138132631.

36. Rafi, M.A.; Mamun, M.A.; Hsan, K.; Hossain, M.; Gozal, D. Psychological implications of unemployment among Bangladesh civil service job seekers: A pilot study. Front. Psychiatry 2019, 10, 578. [CrossRef]

37. Wang, R.T. Modeling corporate social performance and job pursuit intention: Mediating mechanisms of corporate reputation and job advancement prospects. J. Bus. Ethics 2013, 117, 569-582. [CrossRef]

38. Alcañiz, E.B.; Cáceres, R.C.; Pérez, R.C. Alliances between brands and social causes: The influence of company credibility on social responsibility image. J. Bus. Ethics 2010, 96, 169-186. [CrossRef]

39. Vinokur, A.; Caplan, R.D. Attitudes and social support: Determinants of job-seeking behavior and well-being among the unemployed. J. Appl. Soc. Psychol. 1987, 17, 1007-1024. [CrossRef]

40. Huang, J.T. Application of planned behavior theory to account for college students' occupational intentions in contingent employment. Career Dev. Q. 2011, 59, 455-466. [CrossRef]

41. Taylor, S.; Todd, P.A. Understanding information technology usage: A test of competing models. Inf. Syst. Res. 1995, 6, 144-176. [CrossRef]

42. Dhanesh, G.S. CSR as organization-employee relationship management strategy: A case study of socially responsible information technology companies in India. Manag. Commun. Q. 2014, 28, 130-149. [CrossRef]

43. Kanfer, R.; Wanberg, C.R.; Kantrowitz, T.M. Job search and employment: A personality-motivational analysis and meta-analytic review. J. Appl. Psychol. 2001, 86, 837-855. [CrossRef]

44. Liao, Z.; Cheng, J. Can a firm's environmental innovation attract job seekers? Evidence from experiments. Corp. Soc. Responsib. Environ. Manag. 2020, 27, 542-551. [CrossRef]

45. Sparks, M.A.; Radnitz, C.L. Confirmatory factor analysis of the children's eating behaviour questionnaire in a low-income sample. Eat. Behav. 2012, 13, 267-270. [CrossRef]

46. Fornell, C.; Larcker, D.F. Evaluating structural equation models with unobservable variables and measurement error. J. Mark. Res. 1981, 18, 39-50. [CrossRef]

47. Podsakoff, P.M.; MacKenzie, S.B.; Lee, J.Y.; Podsakoff, N.P. Common method biases in behavioral research: A critical review of the literature and recommended remedies. J. Appl. Psychol. 2003, 88, 879-903. [CrossRef] [PubMed]

48. Hu, L.T.; Bentler, P.M. Cutoff criteria for fit indexes in covariance structure analysis: Conventional criteria versus new alternatives. Struct. Equ. Model. 1999, 6, 1-55. [CrossRef]

49. Van Hoye, G.; Saks, A.M.; Lievens, F.; Weijters, B. Development and test of an integrative model of job search behaviour. Eur. J. Work Organ. Psychol. 2015, 24, 544-559. [CrossRef]

50. Searle, R.; Billsberry, J. The development and destruction of organizational trust during recruitment and selection. In Trust and Human Resource Management; Searle, R., Skinner, D., Eds.; Edward Elgar: Northampton, UK, 2011; pp. 67-86. ISBN 9781848444645.

51. Fishbein, M.; Cappella, J.N. The role of theory in developing effective health communications. J. Commun. 2006, 56, 1-17. [CrossRef]

52. Robbins, S.P.; Judge, T.A. Organizational Behavior; Pearson Education: Harlow, UK, 2015.

53. Van Hooft, E.A.J.; De Jong, M. Predicting job seeking for temporary employment using the theory of planned behaviour: The moderating role of individualism and collectivism. J. Occup. Organ. Psychol. 2009, 82, 295-316. [CrossRef]

54. Banerjee, P.; Gupta, R. Talent attraction through online recruitment websites: Application of web 2.0 technologies. Australas. J. Inf. Syst. 2019, 23. [CrossRef] 
55. Esch, P.; Black, J.S. Factors that influence new generation candidates to engage with and complete digital, AI-enabled recruiting. Bus. Horiz. 2019, 62, 729-739. [CrossRef]

56. Sheeran, P.; Webb, T.L. The intention-Behavior gap. Soc. Personal. Psychol. Compass 2016, 10, 503-518. [CrossRef]

57. Jaidi, Y.; van Hooft, E.A.J.; Arends, L.R. Recruiting highly educated graduates: A study on the relationship between recruitment information sources, the theory of planned behavior, and actual job pursuit. Hum. Perform. 2011, 24, 135-157. [CrossRef]

58. Schreurs, B.; Derous, E.; van Hooft, E.A.J.; Proost, K.; de Witte, K. Predicting applicants' job pursuit behavior from their selection expectations: The mediating role of the theory of planned behavior. J. Organ. Behav. 2009, 30, 761-783. [CrossRef]

59. Werbel, J.D. Relationships among career exploration, job search intensity, and job search effectiveness in graduating college students. J. Vocat. Behav. 2000, 59, 379-394. [CrossRef] 